\title{
PLANO DE CONTINGÊNCIA PARA COVID-19 EM INSTITUIÇÕES DE LONGA PERMANÊNCIA PARA IDOSOS: O IDEAL E O POSSÍVEL
}

Yeda Aparecida de Oliveira Duarte' ORCID: 0000-0003-3933-2179

Helena Akemi Wada Watanabe' ORCID: 0000-0002-3951-9091

Luciana Mitsue Sakano Niwa' ORCID: 0000-0002-9342-7454

Pamella Cristina de Carvalho Lucas' ORCID: 0000-0003-3661-3290

Caren da Silva Jacobi" ORCID: 0000-0002-8917-6699

Daniela Aparecida da Silva Rebouças Marcos"II ORCID: 0000-0002-6508-8352

Shirley da Rocha Afonso ${ }^{\text {Iv }}$ ORCID: 0000-0003-1824-0451

'Universidade de São Paulo. São Paulo, São Paulo, Brasil.

"Universidade Federal de Santa Maria. Santa Maria, Rio Grande do Sul, Brasil.

I'"Residencial Israelita Albert Einstein. São Paulo, São Paulo, Brasil.

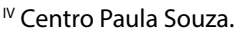
São Paulo, São Paulo, Brasil.

Autor Correspondente: Yeda Aparecida de Oliveira Duarte E-mail:yedausp@gmail.com

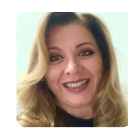

Como citar:

Duarte YAO, Watanabe HAW, Niwa LMS, Lucas PCC, Jacobi CS, Marcos DASR, et al. Plano de contingência para covid-19 em instituições de longa permanência para idosos: 0 ideal e o possível. In: Santana RF (Org.). Enfermagem gerontologica no cuidado do idoso em tempos da COVID 19. 2.ed.rev. Brasilia, DF: Editora ABEn; 2020. p 67-74. (Serie Enfermagem e Pandemias, 2). https://doi.org/10.51234/aben.20.e02.c11

\section{INTRODUÇÃO}

Em 21 de junho de 2020 o Brasil acumulou 1.086 .990 casos de infecções pelo novo Coronavírus com 50.659 mortes registradas oficialmente; três em cada dez casos no mundo são do Brasil( ${ }^{(1)}$. A taxa de mortalidade entre pessoas idosas é mais elevada quando comparada com outras faixas etárias, e dentro do próprio segmento idoso, verifica-se que é ainda mais elevada entre os idosos mais longevos ( $\geq 75$ anos). Em 02 de abril foram registrados 242 óbitos por COVID-19 em pessoas $\geq 60$ anos $^{(2)}$, em 25 de maio, 12.574 óbitos, 69,4\% do total de mortes no país ${ }^{(3)}$ mostrando um crescimento de $5,2 \%$ das mortes de pessoas idosas em 53 dias.

Nas Instituições de Longa Permanência para idosos (ILPIs), antigamente denominadas "asilos", residem pessoas idosas, a maioria $\geq 80$ anos, com multimorbidades (duas ou mais doenças crônicas simultâneas) e frágeis, constituindo, assim, um grupo de elevadíssimo risco para contrair a doença e morrer. Trata-se de uma residência coletiva que concentra uma população altamente vulnerável e, devido à proximidade, compartilhamento de espaços e contato com profissionais com circulação externa a ela é um ambiente de alto risco de alastramento rápido da infecção ${ }^{(2,4,5)}$. São equipamentos da Assistência Social não tendo, em sua maioria, estrutura ou recursos humanos específicos para oferecer cuidados de saúde a seus residentes.

Ainda não se sabe ao certo quantas instituições existem no país. Censo realizado pelo IPEA em 2010 indicava a existência de cerca de 90.000 idosos vivendo nas 3600 instituições ou cerca de $1 \%$ da população idosa do país. Inquérito nacional sobre as ILPIs vinculadas ao SUAS, realizado entre 2016 e 2018, mostrou que aproximadamente 51 mil pessoas idosas viviam nas ILPIs públicas e filantrópicas sendo $65 \%$ semidependentes ou dependentes e, portanto, frágeis. Hoje esse número chega a 78 mil pessoas idosas ${ }^{(6)}$.

As ILPI não são consideradas equipamentos de Saúde, mas da Assistência Social, com interesse da Saúde; públicas 
e privadas, com ou sem fins lucrativos, possuem equipes diversificadas, com ou sem profissionais da área de saúde. São regidas pela RDC $284 / 2005^{(7)}$ que prevê um quadro mínimo de recursos humanos, onde, apenas o responsável técnico e o profissional de lazer têm como pré-requisito formação de nível superior.

Assim, muitas instituições não possuem recursos humanos qualificados, materiais e equipamentos, bem como instalações adequadas para o atendimento de pessoas idosas acometidas por COVID-19(3,4). A capacitação dessas equipes torna-se um grande desafio, mas necessária para prevenir e controlar a contaminação dos residentes, dos trabalhadores que atuam no contato direto com a pessoa idosa e dos profissionais dos serviços de apoio. Inúmeros materiais sobre prevenção e controle da COVID 19 nesses locais foram elaborados pelo Ministério da Saúde, pelas sociedades cientificas, e Vigilâncias Sanitárias de alguns estados e a própria ANVISA buscando auxiliar no controle da pandemia.

Mesmo com o avanço da pandemia no Brasil, não há dados específicos, em nível nacional ou local, sobre casos e óbitos nas ILPIs o que é frequentemente divulgado pela imprensa são casos pontuais. As possíveis fontes de contaminação nesses locais são as pessoas externas, como visitantes, voluntários ou funcionários que, frequentemente, trabalham em outras instituições ou hospitais, e adentram ao local. Como uma medida protetiva, a maioria das ILPIs restringiu as visitas e a saída das pessoas idosas, suspendeu atividades voluntárias e estágios, mas, mesmo assim, isso não impediu sua contaminação.

Europa e Estados Unidos registraram 30 a 50\% de óbitos por COVID 19 nas ILPIs. Essas notícias geraram uma enorme preocupação entre os profissionais, familiares e residentes das ILPIS em nosso meio que, de diferentes formas, buscaram se organizar para evitar a ocorrência de um gerontocídio (genocídio de idosos) local.

As normas preveem o isolamento dos residentes com suspeita ou confirmação de COVID 19, na própria ILPI, entretanto a maioria delas não têm estrutura física, nem quadro de pessoal capacitado para o cuidado de pessoas nessas condições. Uma medida necessária e urgente é que cada instituição conheça a estrutura de apoio que a cerca, identificando os serviços de saúde de referência e estabelecendo um plano de ação conjunto com a autoridade sanitária local, incluindo as tratativas para o transporte de possíveis infectados.

Em instituições onde o isolamento é inviável, deve ser pactuado com os serviços de saúde locais, um fluxo de atendimento para remoção dos casos/suspeitos, para um leito de saúde onde receberão os devidos cuidados e, assim, diminuirá a possibilidade de alastramento da contaminação local. A testagem de casos suspeitos deve ser, também, pactuada. Pessoas com potencial para desenvolver quadros mais graves da doença têm prioridade no atendimento e testagem para o vírus. Diante do resultado positivo para COVID-19 obtido por meio do teste RT-PCR ou imunoglobulina é recomendável a testagem de todos os residentes e funcionários da ILPI ${ }^{(2,4)}$.

É mister a criação de um plano de contingência da doença, adequado às especificidades de cada instituição e a intensificação da higienização das mãos e de práticas sanitárias. Para isso, torna-se necessária a desinfecção de superfícies em áreas comuns, dormitórios e utensílios, a disponibilização de lavatórios com insumos (água tratada, sabonete líquido, papel toalha e lixeira com pedal) e dispensadores de álcool em gel $70 \%$ abastecidos em pontos estratégicos da ILPI, como corredores, recepção, refeitório, dormitórios e áreas comuns ${ }^{(5)}$.

Os profissionais que atuam em contato direto com os residentes bem como as equipes de apoio, como recepcionistas, copeiras, manutenção e auxiliares de serviços gerais devem ser orientados a higienizar as mãos com água e sabonete líquido ou preparação alcoólica 70\%. Tais equipes carecem de equipamentos de proteção individual (EPI): gorro (para procedimentos que geram aerossóis), óculos de proteção ou protetor facial (face shield); máscaras descartáveis e avental impermeável. Para copeiras e auxiliares de serviços gerais, devem ser disponibilizadas luvas de borracha e botas impermeáveis com cano longo e, para os profissionais de saúde, quando existirem, ao realizar aspiração orotraqueal ou outros procedimentos que gerem aerossóis, substituição da máscara cirúrgica pela N95/PFF2 ou equivalente ${ }^{(2,4)}$. A oferta de EPIs precisa ser em quantidade e qualidade suficientes e os profissionais necessitam de treinamentos e capacitações repetidas, além de monitoramento, sobre paramentação e desparamentação pois essa não costuma ser uma prática habitual em muitas ILPIs. 
Devido a heterogeneidade de recursos humanos, de estruturas e de demanda de cuidados nas ILPI no Brasil, esse trabalho busca auxiliar os profissionais envolvidos e atuantes nas ILPIs na execução do plano de contingência prevendo ações planejadas e sistematizada para aplicação a realidade dos cenários existentes.

\section{OBJETIVO}

Discorrer sobre a organização do fluxo de ações para o enfrentamento da COVID-19 nas ILPIs no Brasil.

\section{MÉTODOS}

Reflexão crítica embasada em situação vivenciadas nas ILPIs fundamentadas em publicações nacionais e internacionais sobre a temática. As reflexões propostas buscam nortear o reordenamento das ILPIs e versam sobre a organização de um plano de contingência, orientação aos residentes, familiares, treinamento e capacitação dos trabalhadores da instituição e fluxo de atendimento.

\section{RESULTADOS}

Busca-se, nesse momento, nortear o reordenamento das ações assistenciais nas ILPIs frente a pandemia. Desse modo, um plano de contingência deverá ser elaborado de modo a nortear as ações em casos suspeitos e positivos para COVID-19. A identificação precoce dos sinais e sintomas são diferenciais importantes na tomada de decisão lembrando, aqui, que as pessoas idosas podem apresentar sinais e sintomas obscuros, atípicos ou inexistentes e, assim, podem não apresentar os sinais e sintomas classicamente associados à infecção pelo coronavírus, em especial febre. Qualquer queixa deve ser valorizada e qualquer alteração de comportamento deve ser um sinal de alerta.

O plano de contingência das ILPIs, incluindo medidas preventivas, deverá ser traçado em conjunto com a autoridade sanitária local. Nas instituições onde não houver casos suspeitos ou diagnosticados da doença busca-se evitar, ao máximo, a contaminação local. Deve ainda estabelecer as ações para o cuidado dos casos suspeitos, diagnosticados e para os que retornarem à ILPI após a alta hospitalar. Deve, ainda, prever ações relacionadas aos funcionários que forem contaminados considerando seu afastamento e seu retorno à instituição.

\section{Orientação aos residentes, familiares e trabalhadores da instituição}

- Identificar os funcionários que compõem o grupo de risco (idosos, pessoas com comorbidades. Esses devem ser, preferencialmente, afastados, mas, se isso não for possível, devem ser realocados para funções que evitem o contato com os residentes além de ser garantida a disponibilização de EPIs;

- Restringir visitas, estágios e voluntariado como medida de proteção aos residentes;

- Avaliar se a estrutura física da instituição permite o estabelecimento de espaços para isolamento respiratório e, se existir, deixá-lo organizado para esse fim;

- Estabelecer fluxos internos (fornecedores, materiais, alimentos, roupas) e externos (transporte, transferência para instituições de saúde referenciadas para a pandemia).

\section{Treinamento e capacitação dos funcionários para atuação nesse momento:}

\section{Estrutura de planejamento e tomada de decisão:}

- Identificar e listar os idosos com diretivas antecipadas de vontade e rediscuti-la com o próprio idoso (quando em condições físicas e cognitivas para isso) e com seus responsáveis a fim de facilitar a tomada de decisão em situações críticas. Ressalta-se que as diretivas em questão foram elaboradas para outras 
situações e devem ser revistas nesse momento para as condições da pandemia pois trata-se de doença tratável com possibilidade de cura;

- Reavaliar os fluxos de atendimento às urgências e emergências e disponibiliza-los à equipe assistencial promovendo segurança e agilidade dos atendimentos;

- Formar um comitê destinado ao alinhamento dos fluxos assistenciais, administrativos e operacionais que envolva Gestores e Equipe Multidisciplinar;

- Estabelecer um interlocutor para conversar com as famílias e/ou responsáveis pelo residente.

\section{Estrutura de suprimentos e recursos físicos}

- Dimensionar a necessidade de suprimentos (alimentos, insumos, medicamentos);

- Realizar pedidos semanais de insumos para higiene e EPIs para precaução de contato e aerossóis;

- Fazer uma planilha semanal para balanço entre estoque, consumo e requisições;

- Redimensionar e ampliar os locais onde serão dispostos álcool gel e máscaras descartáveis: recepção, corredores, quartos dos idosos, elevadores, áreas administrativas e assistenciais;

- Incentivar e monitorar o uso de álcool gel e EPIs pelos colaboradores e residentes;

- Realizar campanhas de incentivo à higienização das mãos e uso de álcool gel;

- Treinar e capacitar os profissionais das ILPIs sobre as medidas de prevenção e contenção da COVID-19 inerente à sua rotina de trabalho permitindo a compreensão rápida, apreensão significativa e aplicação prática em seu cotidiano;

\section{Cuidados Assistenciais:}

As ações de prevenção deverão ser instituídas desde a portaria, sendo necessária aferição de temperatura com termômetro infravermelho em todos os colaboradores e visitantes. Se apresentar temperatura maior ou igual a $37,5^{\circ} \mathrm{C}$ será realizado dupla checagem com termômetro digital axilar. Caso o valor da temperatura persista não será permitida a entrada do transeunte e o mesmo deverá ser orientado a procurar o serviço de saúde de apoio para ser avaliado.

Durante essa abordagem os transeuntes serão orientados quanto a higienização correta das mãos e cuidados com a máscara. Calçados devem ser higienizados antes de entrarem na instituição ou devem ser fornecidos propés descartáveis. Devem ser disponibilizados materiais de limpeza para desinfecção de bolsas, sacolas e pertences antes de adentrar a instituição e, após higienização, os mesmos deverão ser colocados em armário localizado em área destinada a esse fim.

É necessário rever a reorganização dos quartos dos residentes e do refeitório, procurando manter uma distância de 2 metros entre eles. Evitar o compartilhamento de escovas de dentes, talheres, pratos, bebidas, toalhas ou roupas de cama. Talheres e pratos devem ser higienizados com água, sabão e poderão ser reutilizados. Banheiros devem ser limpos e desinfectados pelo menos uma vez ao dia.

A equipe assistencial deverá ser monitorada rigorosamente. Na presença de qualquer sintoma, o colaborador deve ser imediatamente encaminhado para o serviço saúde de referência da região para realização de teste COVID-19 devendo ficar afastado até seu resultado e, caso seja positivo, deverá ser afastado seguindo as orientações das autoridades sanitárias. Seu retorno só deve ocorrer após realização de novo teste com resultado negativo e autorização de referência médica do território.

A instituição deve possuir local para que os funcionários se troquem e se higienizem ao chegarem ao trabalho, visando a descontaminação preventiva. Somente após esse procedimento é que poderão entrar em contato com os residentes.

Em decorrência da restrição protetiva proibindo as visitas de familiares ou amigos, as ILPIs devem providenciar estratégias alternativas como o uso de tecnologias (smartfones ou tablets) para realização de "visitas virtuais". 
Aquelas que não dispuserem de tais equipamentos ou apresentam alterações na visão, audição ou motricidade fina poderão utilizar telefones fixos da própria ILPI, com agendamento prévio de horário com a família para a pessoa idosa ser contactada e os equipamentos da administração, como, por exemplo, computadores, que devem ser disponibilizados para esse fim.

Algumas instituições derrubaram seus muros que foram substituídos por grades para, dessa forma, permitir que os residentes vissem e conversassem com seus parentes mantendo distanciamento seguro. Em outras, o contato visual ou abraço dos idosos em familiares vem ocorrendo com a utilização de cortinas de plástico transparente com proteção de braços e mãos. Esta forma de contato precisa ser utilizada com cautela e, a cada idoso e familiar que se abraçam, o plástico deve ser reavaliado de forma a garantir a integridade do mesmo e deve ser realizada sua higienização com álcool 70\% em ambos os lados.

Para que as pessoas idosas possam continuar a tomar sol em espaços comuns, torna-se necessária a criação de um cronograma com distribuição de horários para esta atividade entre os residentes, preservando sempre o distanciamento.

É importante salientar que essas medidas restritivas são medidas de proteção para evitar a contaminação dos residentes. Caso os familiares decidam levar o residente para suas casas devem ter ciência que ele deverá permanecer por lá, pois poderá ser contaminado e se tornar um risco para outros residentes em seu retorno. Caso isso ocorra, deverá permanecer em isolamento até a realização de teste COVID-19 com resultado negativo ou, quando isso não for possível, permanecer em isolamento por 14 dias com monitoramento de sintomas.

Um grande desafio é tratar do idoso portador de alterações cognitivas com preservação motora visto que poderá não compreender as medidas preventivas ou a necessidade de isolamento. Eles demandarão maior esforço assistencial para vigilância e monitoramento.

\section{Fluxo de atendimento ao residente:}

A detecção precoce de sinais e sintomas é imprescindível para que a abordagem seja eficaz e assertiva. Os idosos com sintoma(s) gripal(is) (tosse, coriza, dor de garganta, febre) ou com alteração de comportamento ou de seu quadro de saúde devem:

- Permanecer em seu quarto de origem, com ambiente arejado e com medidas de precaução aérea e de contato;

- Avisar a unidade de saúde de referência para avaliação e realização de teste COVID-19; O diálogo com a Atenção Básica no território tem permitido a presença do médico em alguns turnos na ILPI, como uma medida preventiva e pró-ativa.

No caso da ILPI que contar em seu quadro de RH com médicos, deverá ser solicitada a avaliação do(s) residentes sintomáticos e providenciada a testagem; preferencialmente, na ILPI, evitando-se a exposição do idoso ao risco de contaminação em ambientes externos (laboratórios ou hospitais).

- Encaminhar rapidamente o residente para a referência hospitalar da região caso apresente piora no quadro clinico;

- Se, no $1^{\circ}$ teste dos sintomáticos o resultado for negativo, deve-se realizar o teste de contraprova antes de suspender as medidas de precaução aérea e contato;

- Se o resultado do teste for positivo para COVID-19, transferir o residente idoso para o local preparado para atendimento dos casos específicos de COVID-19 na ILPI (se houver) ou, preferencialmente, providenciar sua transferência para a unidade de saúde referência de tratamento de casos positivos, no território. Deve ser rapidamente providenciado um levantamento dos contatos do caso positivo que devem ser testados e monitorados rigorosamente. 
Reconhecendo-se que a população idosa residente em ILPI, dada sua maior vulnerabilidade, é considerada de alto risco para desenvolver infecção pelo coronavírus, caso entrem em contato com o vírus, torna-se importante planejar uma infraestrutura para possíveis casos confirmados da COVID-19. Através de uma área exclusiva para a assistência aos idosos, caso não seja possível transferi-los para uma unidade de saúde referência para tratamento desses casos, pois, embora não seja a melhor opção, é a mais indicada nessas circunstâncias.

Caso a transferência para uma unidade de saúde não seja imediata ou, não seja possível, deve-se escolher uma área na ILPI de fácil acesso aos elevadores (caso existam) e, o mais importante, com acesso restrito. Deve-se organizar uma antessala com pia e torneira e toalhas de papel, local para acondicionamento de EPIs: máscara N95, gorro, luvas descartáveis, avental descartável, e álcool gel. O número de quartos disponíveis será definido através da estrutura física de cada instituição. Nessa área, os quartos devem ser privativos com identificação na porta sinalizando precaução respiratória e de contato, com pia e dispenser de álcool gel. A paramentação para os colaboradores nesse ambiente deverá ser gorro, propé, óculos de proteção, máscara N95 e roupa privativa. Os aventais deverão ser utilizados somente dentro dos quartos onde deverá haver um hamper para que todas as roupas contaminadas, não descartáveis, sejam colocadas e, posteriormente retiradas pela equipe de apoio com as precauções para materiais contaminados.

O isolamento do residente contaminado deve ter duração de 14 dias e recomenda-se evitar rodízio da equipe assistencial. O residente necessita de atendimento de equipe de saúde que deve monitorá-lo diariamente para intervir, rapidamente, caso haja qualquer agravamento do quadro clínico. Após 14 dias e ausência de sintomas, deve-se providenciar a realização de novo teste para COVID-19, antes de liberá-lo do isolamento.

Nos casos em que o banheiro for compartilhado sem possibilidade de exclusividade aos infectados, a pessoa idosa em isolamento deve ser a última a realizar a higiene corporal e imediatamente após, é necessária a desinfecção do local. Quando estas opções não são viáveis o isolamento pode ocorrer fora da instituição, em hospital ou local específico destinado a receber esta população(4).

Além do treinamento presencial com toda equipe assistencial e de apoio devem ser disponibilizados impressos informativos quanto à correta paramentação e desparamentação, uso correto da máscara e face shield, periodicidade da desinfecção de equipamentos de enfermagem e recursos gerais deste local tais como termômetro, aparelho de PA, entre outros.

\section{Fluxo estabelecido para tratativa de óbitos relacionados a pacientes com suspeita/confirmação COVID-19}

A equipe assistencial deverá estar devidamente treinada quanto a paramentação e desparamentação bem como cuidados com o corpo após óbito.

O óbito deverá ser notificado às autoridades sanitárias e devem ser preenchidas Ficha de Investigação; Questionário de Autopsia Verbal além do Atestado de óbito. A orientação do Ministério da Saúde recomenda a não realização de velórios e funerais durante a pandemia da Covid-19 devido à aglomeração de pessoas em ambientes fechados ${ }^{(8)}$.

Em se tratando de caso suspeito de COVID-19, o médico atestante deve notificar a equipe de vigilância em saúde imediatamente após a informação do óbito. O corpo deverá ser retirado da ILPI, observando as medidas de precaução individual e deverá estar envolto em lençóis e em bolsa plástica para impedir o vazamento de fluidos corpóreos. O quarto do residente falecido deverá ser desinfectado (uso de solução clorada 0,5\% a 1\%) e arejado.

\section{Cuidados com a equipe assistencial e de apoio}

Se a ILPI possuir um local exclusivo para isolamento de casos/suspeitos de COVID-19, uma equipe assistencial exclusiva para atendimento dos residentes deve ser providenciada. Essa deverá ser monitorada e acompanhada pela administração da instituição que deve apoiá-la tanto no aspecto técnico quanto emocional. 
Recomenda-se conversas semanais com a equipe assistencial e de apoio visando reforçar as orientações e identificar sobrecarga. Deve-se reforçar as recomendações relativas às precauções e monitorar a existência de contaminação entre eles. É possível afirmar que muitos funcionários mantém o conhecimento sobre as medidas de prevenção do COVID-19. No entanto, inerente à sua rotina de trabalho acaba por ignorar todos os procedimentos necessários para controlar a infestação viral. Tal condição evidencia a oportunidade de se repensar o processo de educação continuada dos colaboradores, e avaliar condições de saúde física, mental e emocional do colaborador.

Os planos de capacitação técnicas devem incluir o conhecimento teórico e técnico a respeito das medidas de contenção da contaminação de COVID-19. Necessitam permitir a compreensão rápida e a apreensão significativa de todas etapas de prevenção da contaminação. Ou seja, os treinamentos necessariamente precisam ter momentos de apreensão do novo conhecimento, reflexão sobre a relação teórica e a observação na realidade e desenvolvimento do hábito por meio da prática em campo. Outro aspecto importante a considerar é o tipo de treinamento e o momento de prevenção da contaminação, concentrando a orientação na atribuição de trabalho do funcionário da instituição.

É preciso realizar treinamentos específicos para cada área de trabalho e, para isso, o gestor necessita refletir sobre qual ação de trabalho é executada em determinado setor e qual etapa de prevenção precisa ser concentrada. É importante destacar que, os treinamentos e as medidas de educação continuada para todos membros do quadro de funcionários da ILPI são planos eficazes para manter uma equipe de trabalho sincronizada às rotinas de trabalho e sintonizada na identificação de situações potencialmente contaminantes e, portanto, elaborar um plano de contingência contribuirá para minimizar a transmissão da COVID-19.

$\mathrm{Na}$ ocorrência de casos suspeitos/positivos entre os funcionários, eles devem ser encaminhados ao serviço de saúde de referência para testagem e, devem ser imediatamente afastados imediatamente enquanto aguarda o resultado. Se o resultado for positivo deverá ser orientado a ficar 14 dias em isolamento sendo monitorado, diariamente, via telefone e/ou telemedicina quando disponível. Os idosos que estavam sob seus cuidados deverão ser isolados e testados. Após 14 dias repete-se o teste, se negativo coleta-se outro após $24 \mathrm{~h}$, se o $2^{\circ}$ resultado for igualmente negativo deve-se aguardar liberação médica para retornar ao trabalho. Se permanecer positivo após 14 dias repete-se o teste entre 5 e 7 dias. Todos devem ser orientados que, em caso de alterações no quadro clínico, devem dirigir-se ao hospital de referência para avaliação e tratamento adequados.

Ressalta-se que as que as informações assistenciais /clínicas são confidenciais e, assim, não devem ser comentadas com outros residentes e/ou colegas de trabalho. A administração da ILPI é responsável pela elaboração, monitoramento e controle dos casos suspeitos, confirmados, negativados e óbitos tanto entre os residentes quanto entre os colaboradores. As notificações devem ser realizadas aos órgãos sanitários fiscalizadores.

\section{CONSIDERAÇÕES FINAIS}

As ILPI estão se esforçando para a realização de boas práticas no enfrentamento da pandemia de COVID-19. Numerosas exigências são acrescidas diariamente para um serviço que, cotidianamente, está sobrecarregado, caso de diversas ILPI filantrópicas sem fins lucrativos. Contudo a necessidade de um plano de ação voltado a prevenção e um plano de contingência para os casos da COVID-19 são fundamentais para garantir a segura e proteção dos idosos e evitar a ocorrência de um gerontocídio como o noticiado em outros países.

\section{AGRADECIMENTO}

Ao Departamento Científico de Enfermagem Gerontológica da ABEn Nacional.

\section{REFERÊNCIAS}

1. Conselho Nacional do Secretários de Saúde. Painel CONASS COVID-19. [Acesso em: 21 junho 2020]. Disponível em: http:// www.conass.org.br/painelconasscovid19/ 
2. Brasil. Ministério da Saúde. Secretaria de Vigilância em Saúde. COE-COVID-19. Boletim epidemiológico 6. 3 de Abril de 2020. Disponível em: https://portalarquivos.saude.gov.br/images/pdf/2020/April/03/BE6-Boletim-Especial-do-COE.pdf (a)

3. Brasil. Ministério da Saúde. Secretaria de Vigilância em Saúde. COE-COVID-19. Boletim Epidemiológico Especial 17. 25 de maio de 2020. Disponível em: https://www.saude.gov.br/images/pdf/2020/May/29/2020-05-25---BEE17---Boletim-do-COE.pdf (b)

4. Frente Nacional de Fortalecimento às Instituições de Longa Permanência para Idosos. Giacomin KC (coord). Instituições de Longa Permanência para Idosos e o enfrentamento da pandemia de COVID-19: subsídios para a Comissão de Defesa dos Direitos do Idoso da Câmara Federal - Relatório técnico. Frente Nacional de Fortalecimento às Instituições de Longa Permanência para Idosos. Brasília: abril, 2020. Disponível em: https://sbgg.org.br/wp-content/uploads/2020/06/ Relato\%CC\%81rio-final-FN_fichaC.pdf (a)

5. Nunes VMA et al. COVID-19 e o cuidado de idosos: recomendações para Instituições de Longa Permanência [Internet]. Natal, RN: EDUFRN, 2020 [citado 2020 Jun 12]. Disponível em: https://repositorio.ufrn.br/jspui/handle/123456789/28754.

6. Camarano AA, Kanso S. As instituições de longa permanência para idosos no Brasil. Rev Bras Estud Popul 2010;27:232-5. doi:10.1590/S0102-30982010000100014

7. BRASIL. Agência Nacional de Vigilância Sanitária. Resolução da Diretoria Colegiada № 283 de 26 de setembro de 2005. Disponível em: http://bvsms.saude.gov.br/bvs/saudelegis/anvisa/2005/res0283_26_09_2005.html

8. Frente Nacional de Fortalecimento às Instituições de Longa Permanência para Idosos RODRIGUES RAP (Coord) Boas Práticas para as Instituições De Longa Permanência Para Idosos no Enfrentamento da Pandemia de COVID 19: estratégias e protocolos. Maio, 2020. Disponível em: https://sbgg.org.br/wp-content/uploads/2020/06/FN-BOAS-PRA\%CC\%81TICASFICHA-C.pdf (b) 